\title{
SOLIPSISM: A PERCEPTUAL STUDY
}

\author{
DALE; E. SMITH
}

Saint Andrew's School

Few issues have been as persistent and recurring a theme as solipsism. Modern philosophy traditionally has managed the starting point of solipsism by translating it into a transcendental and apodictic condition for knowledge. Solus ipse, the contention that "I alone am," is reworked to exploit its most valued feature, the analytic clarity which the thought process achieves when restricted to its own operations. In this manner philosophy has endeavored to gain certain knowledge of how the mind embraces the domain of knowledge, the sensory world.

As effective as transcendental thought has been in managing solipsism, it does not resolve problems inherent in the position. In emphasizing the theme of self-knowledge or introspection, philosophy erects a barrier between the mind's capacity to know, an internal process, and the world known, an external domain. The external world is known by means of consciousness' internal schemata or patterns of thought. Philosophical relations which describe this process-inference, association, analogical apperception-all bear witness to the inability of consciousness to escape its own sphere of operations. Far from overcoming the pitfalls inherent in solipsism, modern philosophy shows itself to be solipsism's most ardent defender; the repression of the external world in favor of a constituting consciousness amounts to a mere restatement of the solipsistic thesis.

The motivation behind the treatment of solipsism discussed above is a classic one. Philosophy has traditionally distrusted the sensory world and the perceptual process through which the world is presented to consciousness. In view of the limited success enjoyed by this approach to solipsism, it is legitimate to inguire whether perception merits such distrust. If not, is it instead the treatment which perception receives at the hand of transcendental exposition which prevents a resolution of the problem? The objective of this es- 
say is to explore the second alternative; using the later writings of Maurice Merleau-Ponty as our guide, we shall examine how the perceptual experience of the world which in the hands of transcendental analysis gives birth to solipsism may also offer a resolution to this issue.

Let us begin by considering three categories which would cover most versions of solipsism. They are: egoistic solipsism, which defines reality as the disposition or behavior of the subject; epistemological solipsism, which states that one's immediate experience is primary while attempting to explore the possibility that knowledge itself does not owe its entire organization to a constituting consciousness; and metaphysical solipsism, which is more radical, claiming that not only is one's immediate experience primary. but also that one cannot penetrate or go beyond such experience.

Merleau-Ponty's analyses of the first two categories lead to a precise formulation of the philosophical problems which attend solipsism. He rejects egoistic solipsism on the grounds that the position can reveal nothing about the immediate relation of consciousness to world. The egoistic self is not a primary element of experience; it is rather a reflective reconstruction. The approach taken by epistemological solipsism is more promising. It argues that solipsism arises from the failure of philosophy simultaneously to account for both the primacy of consciousness' grasp of the world and the existence of a world whose structures differ from the internal arrangement of consciousness. Further, notes MerleauPonty, epistemological solipsism also suggests how the impasse found in the transcendental method may be overcome. A three-fold analysis is required. First, solipsistic consciousness must be described anew, free from traditional preconceptions. Secondly, the world must be examined for structures which differ from the patterns or associations of consciousness. Finally, it must be shown how these wordly structures are present or visible in consciousness' immediate grasp of the world. The primacy of consciousness and the uniqueness of the solipsistic understanding must be admitted while maintaining that the solipsistic grasp of immediate experience nonetheless bears the imprint of a larger objective order.

The third category, metaphysical solipsism, underscores the difficulties which solipsism presents human expression. One of the reasons solipsism has been a recurring issue is because our means of expression, thought and speech are viewed as a unique or private possession of consciousness. According to the doctrine 
espoused by a metaphysical solipsism, communication between consciousness is possible because they each participate in a shared construct, language. Language is a vocal and written mirror of consciousness! operations; it serves as a pre-established pathway linking these islets of expression. Once again we confront the problem found in epistemological solipsism; consciousness is the dominant partner in the relationship of thought to world. As a result, the world is reduced to an abstract domain where past and future stand on equal footing with the present. We find no conception in metaphysical solipsism of the world as an immediate presence participating in consciousness.

There exists between epistemological and metaphysical solipsism a reciprocal relationship and a mutual dependency upon one another. Epistemological solipsism proposes a new theory of knowledge. In so doing, it opens the possibility of a philosophical explanation of solipsism which avoids the antagonistic stance which consciousness adopts toward the world. If the theory of knowledge suggested by epistemological solipsism is valid, then it must be vindicated by experience. A crucial test of epistemological solipsism is its ability to provide an alternative to the theory of communication espoused by metaphysical solipsism. The value of metaphysical solipsism then lies in the fact that it provides a testing ground where the theory of knowledge proposed by epistemological solipsism may be verified. Taken together the two descriptions offer a resolution to the problem of solipsism. Merleau-Ponty employs the three-fold analysis proposed by epistemological solipsism to present a new model of experience. He then retraces his steps to demonstrate how expression streams forth along the same pathways discovered by epistemological solipsism.

The first step in formulating a new explanation of solipsism is to define anew the relation of consciousness to world. Merleau-Ponty formulates our immediate experience of the world in the following manner:

The world is what I perceive, but as soon as I express its absolute proximity, it also becomes, inexplicably, irremediable distance. [1]

Human consciousness begins as unmediated contact with the world; consciousness and world are undifferentiated. As the eyes focus upon some visible thing--a setting or an object--the world effaces itself in favor of the thing seen.[2] Consciousness applies 
itself to what is seen and this alone commands its attention.

In the description of fered above, consciousness is no longer an active agent which structures the passive domain of the sensory world. Beneath the judgments made by solipsistic consciousness there is a prior solicitation of consciousness by the world; every perceptible which becomes the object of consciousness is a partial image or cross-section of the world extracted from the perceptual order. The perceptual process is a conversion of the larger perceptual order into a situated and private perspective. [3]

Merleau-Ponty's theory of perception as a conversion process upholds the integrity of both consciousness as a unique grasp of the world and the world as an independent structure. The solipsistic or private aspect of one's immediate experience arises from the perspectival nature of human perception. Merleau-Ponty insists that the uniqueness of my view of the world arises from the manner in which thought completes the perspectival image presented by the world. In order to connect one perspective to the next, thought executes a series of judments about the object seen. These judgments integrate the perspective, which has been uprooted from its perceptual context, into a new order, which is arrayed around the perceiver. Thought weaves a connective thread which joins one perspective to the next, a cohesive pattern which I rightly identify as mine alone. And yet, while this world view bears the unique stamp of solipsistic "consciousness, the basic perspectives from which the solipsistic view is fashioned are carved from an independent perceptual world which subtends consciousness and its judgments.

Conversion can best be understood by appealing to an example of the process itself. A suitable example may be found in the experience of watching a film. Each viewer in the theater has a unique understanding of the drama unfolding on the screen; each structures or interprets the film differently. However, the different interpretations are not entirely solipsistic, for all interpretations draw upon the same sequence of settings, structures, and sounds. Every analysis of the film is carved from the same domain, and it is this common possession, this objective network of relations, which links all interpretations to the 'real' world. Any interpretation of the film is implicitly the measurement of the divergency between the original source and the subject's arrangement of that source. In the theater, as in perception, one never controls the source; in both cases there remains a vital link between consciousness and its source while, at the same 
time, the source retains an independent and autonomous structure.

In the example above, cognition, the process through which we arrive at judgments, is shown to be a secondary form of knowledge. Logically prior to the solipsistic sphere of cognition we find a perceptual consciousness which makes judgments possible. Perceptual consciousness is not guided by cognition; it takes its bearings from the logic of immediate experience. Consciousness has its origin in the perceptual process through which the world first offers itself to consciousness.

The redefinition of consciousness as an openness upon immediate experience indicates that the world has an active and original role to play in senseconstitution. The second step in the study of epistemological solipsism is to examine the birth of consciousness within the perceptual world in order to learn the nature of the objective world.

Conscious awareness of the world is achieved at that moment when an object crystallizes before my gaze. This very process, which Merleau-Ponty describes as a 'redoubled negation'., reveals a labor of the world upon consciousness. The initial recognition of myself as both a perceiver and a consciousness occurs when an object comes into focus. At that moment, I become aware of myself in a negative fashion; $I$ am not the thing seen--the table or the picture--since I am somehow removed from it. There are two steps in this process, an initial divergence from self which immerses the perceiver in the world, followed by an immediate negation of the world in favor of consciousness and its manifold powers. This second negation, through which the world presents itself as a series of perspectives, explains the emergence of consciousness. The initial recognition of myself as a conscious entity transpires when my distance from the object arouses within me an awareness of my place within the world. Selfconsciousness is gained through the perceptual interaction of my sight with objects; self-consciousness is a temporal phenomenon.

The birth of consciousness within the realm of immediate experience affords us an insight into the world responsible for the very possibility of selfconsciousness. The cycle of redoubled negation is completed at that moment, described earlier, when the world appears to recede and the object seen commands my attention. The recession of the world and the predominance of the perspective which supercedes it is not an act willed nor controlled by the subject. It is a mistake to view perspective which alone remains when perception gains complete clarity as a "mental 
representation" of the world. since it is not my creation, the perception should be viewed as the end result of a process which owes nothing to my constituting capabilities; perspectives emerge according to a well-defined logic of vision. [4]

vision is not a series of discrete perceptions, but rather a continued cycle of redoubled negation. For example, as I move around an object, one perspective dissolves and another emerges. The emergence is never abrupt, it is always a transition whereby an object-which, in perception, presents itself not as a substantial thing, but rather as a composition of determinate size, shape, and color--is replaced by another such object as my eyes shift their focus. The objects seen are various combinations or concatenations of these basic properties of the perceptual world. The meaning of perception is structured by the dimensions of the perceptual world, the properties which it contains and the relationship of size and color to shape.

If the process of conversion is viewed from outside immediate experience, it can be seen how the independent properties of the perceptual world not only provide the material or subject matter of consciousness, but how they also establish the very logic of sense-constitution. Viewed from the outside, the conversion of the objective properties of perception into perspectives is a "peeling-off" effect. As the perceiver moves around an object, different configurations of properties coalesce into a changing series of perspectives. The basic patterns of sense which consciousness forms of the object are predetermined according to the possible concatenations implicit within the perceptual schema of the world; by moving in one direction or the other, consciousness activates one of these objective perceptual patterns.

When the perceptual process is viewed from within immediate experience, through redoubled negation, and from without, through the conversion theory of perception, a balanced view of consciousness and world emerge.[5] The most basic features of consciousness-its self-awareness and its comprehension of perceptual patterns--arise through the effects of the world upon consciousness. This dependence of consciousness upon the world does not jeopardize the autonomy of consciousness, for the meaning of the perceptual setting and its sense-patterns are still determined by the perceiver in three ways. First, and most basically, the meaning of the perceptual setting depends upon the movement of the body: traversing the same setting by two different routes yields two different sense-patterns. Secondly, the acts of judgment performed by consciousness guarnatees a unique 
description of the world. Finally, with selfconsciousness comes the ability to remember, the ability to remember past judgments in turn permits a comparison of different meaning patterns. The result is a consciousness capable of understanding the world in a more diverse and creative manner.

The first two steps of Merleau-Ponty's analysis of epistemological solipsism eliminate the first barrier of solipsisin by demonstrating, through an appeal to immediate experience, that consciousness itself is not solipsistic, for it is organized through its exchange with the world. This model of experience still remains solipsistic, however, for within immediate experience the perspective is given but the objective world is not; the world and its meaning patterns were described from a position outside of perceptual consciousness. This is a grave difficulty, for perspectives, by their very nature it seems, have a very precarious and often suspect hold upon the world. In the third step of his study, Merleau-Ponty explains how immediate experience bears the imprint of the larger objective order from which our thoughts and views arise.

According to Merleau-Ponty, others provide verification of the objective order within immediate experience. The possibility of an encounter with another is guaranteed by the doctrine of positionalized consciousness. Since consciousness is an openness upon the world, the perspective I have of the world is mine only by virtue of my position within the world.

What I see is not mine in the sense of being a
private world. Henceforth the table is the
table; even the perspective views which I have of
it and which are bound to the position of my body
are part of being [the world] and not of myself;
even the aspects of the table that are bound to
my psychophysical constitution--its singular
color if I am color-blind and the table is
painted red--are still part of the system of the
world. [6]

It is possible for another to intervene in immediate experience because the world is not of my making.

When I become aware of another's gaze intervening between myself and the object seen, an uneasiness tears at my solipsistic understanding of the world. The other is a silent interlocutor in immediate experience; under his gaze I become objectified. His look freezes me in space and time. As Merleau-Ponty notes, the other 
- . summons me to keep the promises I made when I admitted that I was nothing and was surpassed by being [the world].[7]

Others capture from the outside the conversion of the world into a series of perspectives. They view the cohesiveness of the object seen which, under my eyes, disintegrates into a series of perspectives. In short, the other reflects back to me the interplay between my perspectives and the world:

This exterior [the other] at the same time confirms it [my consciousness] in its particularity, renders it visible as partial being to the other's look and connects it back to the whole of the world. [8]

Without speaking, the other's presence brings the realization that my perceptual experience is of a world in which he too participates. And, when he moves, in order to avoid the chair before me, or to pick up an object captured by my gaze, I gain verification of the connection between my perspective and the world.

The study of epistemological solipsism is in effect an archeology of vision. Its three analyses amount to an excavation of immediate experience which uncovers an objective world sustaining consciousness. The new model of experience advanced by Merleau-Ponty shows consciousness to be an intersubjective rather than a solipsistic enterprise.

If Merleau-Ponty's model of immediate experience is, as he suggests, a restatement of the very structure of experience, the model must be vindicated by experience. The study of epistemological solipsism has prepared the way for such a test by restricting solipsism to the highest sphere of consciousness, that of cognition. Here we rejoin the issue of metaphysical solipsism. While our understanding of the world issues from a common source, there is no guarantee that the means by which I understand the world (thought), and the means by which thought is expressed (speech), have any meaning for others; it is the contention of 'metaphysical solipsism that thought and speech are a private language, an inventory of my solipsistic state. The final resolution of solipsism requires that thought and speech be shown to exist, in prototypical form, within immediate experience; communication must be traced to an origin in the objective world. [9]

It is Merleau-Ponty's contention that the self does not create its own thoughts any more than it creates its own perceptions; thought arises through the mutual 
involvement of the world and the perceiver within vision.

Iminediate experience holds a clue to the nature of thought. Consciousness does not constitute perception. It witnesses, through the process of redoubled negation, that which is perceivable from the position we occupy within the world; the perceptual world is a shared dimension. The activity of perceiving is an uprooting of the perceivable object from its surroundings. In order to perceive something, perception differentiates a certain size, shape, and color from other such configurations, which now serve as its background. It is important to note that the object seen and its background have the same ontological status for they are interchangeable; what is an object from one vantage point may serve as background for the next, as my focus expands or contracts. Thought for Merleau-Ponty is the attempt not only to join perspectives to the world, as noted earlier, but also to connect consciousness and world in a very fundamental manner; thought expresses the relationship between the visible object and the invisible background which together furnish consciousness with its basic sense of the world. The connection of perceiver to world accomplished by thought is no longer a private connection; thought is the prolongation of perception to include the objective structure of vision suppressed in immediate perception.

In their most basic form, thoughts are expressions of location, contrast, and intensity. Merleau-Ponty asserts that all relational knowledge, knowledge upon which more abstract accounts of the world rest, is garnered from this network between figures, and between figure and background, which exists within the objective structure of vision. The contrasts between figure and background spawn our basic ideas of depth, quality and proportion. The contrasts between figures furnishes consciousness with its basic understanding of the use-value of objects. [10] This can be seen anytime consciousness is presented with something foreign to its experience; consciousness' first effort is to adapt the object to the situation in order to determine its use or meaning.

Merleau-Ponty's description of experience contests the notion that cognition is entirely private. Thoughts or judgments are not a priori standards by which an indeterminate reality is measured, for the situation here is reversed; the basic categories of thought-quantity, quality, relation and modality--are presented by vision and modified through experience.

The description of thought given by Merleau-Ponty points to an unconscious origin in the perceptual 
world. At this level we are normally unaware of our use of thought; this level cannot, therefore, represent the highest level of cognition. The highest function is reserved for the self-conscious direction of thought by speech into a verbal thematization of the world; it is through speech that consciousness expresses its knowledge of itself and the world. Every thought expressed through speech is a verbal perspective on the world which completes the meaning of perception by detailing the thing seen, its background, and the relationship between the two. We must now discover how speech humanizes thought while also documenting the continued participation of speech in the intersubjective process of vision.

Merleau-Ponty observes that the promotion of vision to speech is attended by problems which did not face thought. Where vision presents itself in a manner that demands very little of thought, speech is a more creative mode of cognition. If two perceivers are situated in the same room, while we may grant that the scene presented to each is identical, their expressions of the settings may well be completely different. Merleau-Ponty recognizes the differences between our verbal thematizations and yet does not feel that this difference jeopardizes his claim of a common origin for language. Speech, he notes originates as a private or egocentric language. However, while the means by which we speak is personal, that about which we speak is either a shared perceptual possession or an extrapolation from such a perception. Speech arrays the world around the situation within the world which consciousness occupies. Speech directs attention to some aspect of the world by exposing certain patterns which have caught its attention and, while it is true that the consciousness which speaks has a history and an intentionality of its own, it is also true that the whole effort of speech or elocution aims at calling attention to some form of experience which has at its heart a relationship first suggested by the world; speech remains bound to the unconscious and objective structure of thought.

Proof that egocentric language has an objective quality is provided by my verbal interaction with others. Merleau-Ponty observes that:

others present to me in their own fashion what will always be invisible to me, what I will never directly witness . . . a certain difference in terms of dimensions which are from the first common to us. [11] 
The other, who witnesses my understanding of the world from outside the flow of consciousness, reflects back to me aspects of my worldly incarnation which are opaque to me; the other shows me important aspects of my very nature of which I would otherwise be unaware. The speech of others also connects my world, the range of my vision, to the objective matrix which undergirds all consciolisnesses. Let us examine the view of language which the completed circuit of vision-consciousness, object and other--presents.

Egocentric speech is by itself the statement of consciousness' understanding of its situation; its views are partial and its hold on the world is precarious. The speech of others is both informative and corrective. The differences between my expression and that of others is a difference in respect to the shared structure of the world. Language and communication are a constant attempt by consciousnesses to express the meanings of the world which all have in common; communication is always held together by our mutual situation. Language is neither solipsistic, nor is it a synthesis of discrete thinking units. It is the constant attempt to clothe in human meaning a world of contrasts which first evoked thought; language has as its aim the narrowing of the gap between our seemingly private perspectives on the world. the very project of communication seems to have as its aim the coincidence of consciousnesses with the objective world.

Merleau-Ponty's study of thought and speech drives solipsism from its final refuge, the sphere of cognition. Speech and thought are not entirely private, since each is but the internalization of the mute world which sustains both. The key to language is to be sought in consciousness' participation in the world rather than in the sturcutre of formal grammar; language is constantly being modified as speech brings new facets of the world to light.

In the final analysis, Merleau-Ponty shows solipsism to be a byproduct of philsoophical analysis, and not a paradox of experience itself. While there is a unigue grasp of the world which is the birthright of each consciousness, it is also true that consciousness has an objective side; the world which structures consciousness and which is responsible for selfawareness is a shared dimension. Philosophical solipsism arises when identification of self-awareness with cognition forces a rupture with the sensory world.

The restoration of the world to its fullness provides an attractive alternative to the impasses presented by transcendental philosophy. By reconciling cognition with the sensory world Merleau-Ponty 
eliminates the gap between reflection and that which is reflected upon, while still preserving the necessary distance between the world and consciousness required by thought; this distance is guaranteed through the receding character of vision, whereby perspectives never completely coincide with the world.

Merleau-Ponty's extension of mind to include what is often and disparagingly referred to as the 'mundane' world offers two distinct advantages. First, in the area of epistemology, social theory, and political philosophy, it permits renewed investigation, unfettered by the extremes of nominalism and realism. Words do not merely lend meaning to an inderterminate reality (nominalism), nor is the conceptual reality of language a transcendent realm, independent of discrete appearances; for Merleau-Ponty, the activity of naming opens a pathway to the always transcendent objective world within which the collective nature of mankind, class consciousness, and knowledge are to be found. The recovery of the worldly aspects of these notions could prove to be of vital importance to philosophy. Secondly, and perhaps most importantly, the model of the world provided Merleau-Ponty invites and demands validation at every level--perceptual, linguistic, and social. The objective world described is the same reality with which the psychologist, the linguist, the sociologist, and the scientist is concerned. MerleauPonty's preliminary sketch of the world is not limited to philosophical research; it allows confirmation, rejection, or modification by all ot the "sciences of man'. This willingness of Merleau-Ponty to open philosophy to the world is perhaps his most striking achievement. 
${ }^{1}$ Maurice Merleau-Ponty, The $\frac{\text { Visible }}{\text { and }}$ the Invisible, trans. by Alphonso Lingis
Northwestern University Press, 1968), p. 8.

2 In effacement, the world retreats to ground and is superceded by the figure which captures the perceiver's attention. To borrow from the language of Phenomenology of Perception, the visible object becomes the figure and the world becomes the fond or worldly backdrop which sustains the appearance.

${ }^{3}$ In the first chapter of The Visible and the Invisible, Merleau-Ponty introduces the concept of conversion. He writes: "In other words, we are catching sight of another operation besides the conversion to reflection, more fundamental than it. . . " $p$. 38) Perceptual conversion is this fundamental operation. If the perceiver enjoys direct access to the world, there can be no reflective consciousness intervening between the world and the perspective. Accordingly, Merleau-Ponty explains that the process of vision is itself a conversion of the world into perspectival patterns of meaning. The term conversion emphasizes that the world and the perspective are not of two different orders, but rather that the perspective is the world converted into a form comprehensible to man's psychophysical constitution.

${ }^{4}$ The term 'vision' refers to the entire perceptual process described in conversion; when speaking of the situated perceiver, the terms 'perception' or 'perspectives' shall be employed.

$5_{\text {The relationship of consciousness to world }}$ discussed here is drawn from Merleau-Ponty's analysis of Sartre's conception of consciousness as a nothingness and Being as positivity, found in chaper two of The Visible and the Invisible. Merleau-Ponty first criticizes the shortcomings of Sartre's approach, and then adapts these concepts to the experience of vision. I have here adopted Merleau-Ponty's revision of Sartre since it allows a clear contrast to the traditional doctrines of consciousness and world. Later in The Visible and the Invisible these concepts (which are working tools at best) are replaced by a model of Being which surpasses the logical dilemmas of being and nothingness. For our purposes, however, these 
preliminaxy terms present a clearer model of MerleauPonty's approach to solipsism. 57.

${ }^{6}$ Merleau-Ponty, The visible and the Invisible, $p$.

7 Ibid., p. 58, my insertion.

${ }^{8}$ Ibid., p. 63, my insertions.

${ }^{9}$ Communication here refers to the network of meaning which holds between thinking and speaking subjects. The relation of communication to one's thoughts and speech is parallel to the relation of vision to perception discussed earlier. Language for Merleau-Ponty is interchangeable with communication.

${ }^{10}$ The contrast between figures is sustained by the continuous fabric of perception through which perceptual structures are alternately figures and reliefs. The contrasts between figures are an index first established by the perceiver and hence appears, at first glance, not to be a natural relation. However, as we shall see, this relationship between firgures is by no means a reflective reconstruction, since the meaning which obtains between figures remains bound to the perceptual setting from which they arise. Thus, claims Merleau-Ponty, even man-made relations are sustained by the perceptual world, a view which has an important role to play in his model of communication. 82 .

${ }^{11}$ Merleau-Ponty, The visible and the Invisible, p. 